\title{
Participatie van managers in het budgetproces
}

\author{
Een evaluatie van empirisch onderzoek
}

\section{Drs. M. van Dijk}

\section{Inleiding}

Budgettering (dat wil zeggen het vaststellen van budgetten voor verantwoordelijke managers en het vervolgens evalueren van hun activiteiten aan de hand van deze budgetten) is een belangrijk hulpmiddel voor de besturing en beheersing van organisaties.

Budgettering wordt in de praktijk zeer veel toegepast. Uit een onderzoek van Umapathy (1987) onder 402 Amerikaanse bedrijven bleek dat in $97 \%$ van deze bedrijven budgettering werd toegepast.

In de loop der jaren is zeer veel geschreven over de eisen waaraan een effectief budgetsysteem dient te voldoen. Eén van de onderwerpen die hierbij veel aandacht hebben gekregen is de mate waarin managers inspraak dienen te krijgen bij de vaststelling van de budgetten (gewenste mate van budgetparticipatie). De meeste schrijvers zijn van mening dat een ruime mate van budgetparticipatie zeer gewenst is omdat anders de budgetten door de managers niet geaccepteerd zullen worden hetgeen de prestaties nadelig zal beïnvloeden. Zo is bijvoorbeeld Otley (1987) van mening dat 'the only way to ensure that a budget is accepted by a line manager as a reasonable standard against which his/her future performance is to be assessed, is to allow him/her to participate in the budget-setting process'.

Andere schrijvers zijn echter van mening dat budgetparticipatie ook belangrijke nadelen heeft. Bouma (1982) merkt bijvoorbeeld op dat 'meer participatie meer tijd, aandacht en inspanning vergt, terwijl zij bovendien het gevaar inhoudt dat de gebudgetteerden in hun (deel)-begrotingen 'speling' gaan inbouwen in de vorm van doelbewuste onderschatting van opbrengsten en overschatting van kosten'.

Bij zulke grote verschillen met betrekking tot de wenselijkheid van budgetparticipatie dient empirisch onderzoek uitsluitsel te geven. Dit onderzoek is op uitgebreide schaal ook gedaan.

In dit artikel zullen we de resultaten van dit empirische onderzoek bespreken. Hierbij zal blijken dat dit onderzoek op een aantal punten echter onduidelijke en strijdige resultaten heeft opgeleverd. Vervolgens zullen we nagaan wat de oorzaken zijn van deze beperkte resultaten. Hierbij zal blijken dat dit vooral wordt veroorzaakt doordat onvoldoende rekening is gehouden met de verschillende effecten van budgetparticipatie terwijl verder ook een aantal methodologische beperkingen van het verrichte onderzoek aan de beperkte resultaten heeft bijgedragen.

\section{De resultaten van empirisch onderzoek naar de gevolgen van budgetparticipatie}

Vooral tussen 1970 en 1990 is veel empirisch onderzoek verricht naar de gevolgen van budgetparticipatie; verreweg het meeste van dit onderzoek is verricht in de vorm van survey-onderzoek'.

Drs. M. van Dijk heeft Bedrijfseconomie (1974) en Accountancy (1981) gestudeerd bij de EUR. Hij is als universitair hoofddocent verbonden aan de Economische Faculteit van de RUG (vakgroep Accountancy). 


\section{MAB}

Hierbij is vooral onderzoek gedaan naar het effect van budgetparticipatie op de attitudes, arbeidsbevrediging en prestaties van de participerende managers en naar de invloed van budgetparticipatie op de omvang van budgettaire slack.

In bijlage 1 is een overzicht gegeven van de diverse empirische onderzoeken waarbij per studie is aangegeven of een positieve relatie (dat wil zeggen budgetparticipatie leidt tot hogere arbeidsbevrediging, prestaties enzovoort), een negatieve relatie (idem: lagere), een niet-significante relatie (dat wil zeggen budgetparticipatie heeft geen significante invloed op de arbeidsbevrediging enzovoort) of een 'contingency-relatie' (dat wil zeggen budgetparticipatie leidt in sommige omstandigheden tot bijvoorbeeld een hogere arbeidsbevrediging maar in andere omstandigheden juist tot een lagere) werd gevonden. Voor ieder van de onderzochte gevolgen is getotaliseerd in hoeveel studies een positieve, negatieve, niet-significante of een contingencyrelatie werd gevonden.

Uit dit overzicht blijkt het volgende:

1 Inspraak bij het vaststellen van budgetten leidt tot een verbetering van attitudes, arbeidsbevrediging en motivatie bij de betreffende managers.

Figuur 1
2 De invloed van budgetparticipatie op de omvang van budgettaire slack is onduidelijk. In twee studies bleek budgetparticipatie namelijk een vergroting van de slack tot gevolg te hebben, in drie studies juist een verkleining en in twee studies werd geen verband gevonden tussen budgetparticipatie en budgettaire slack.

3 Ook de invloed van budgetparticipatie op de prestaties van managers is niet duidelijk. In zes studies bleek budgetparticipatie een positieve invloed te hebben op de prestaties, in twee studies werd een negatieve invloed gevonden en in zes studies bleek budgetparticipatie geen invloed te hebben op de prestaties. In acht studies bleek de invloed van budgetparticipatie op de prestaties afhankelijk te zijn van de omstandigheden (contingency-variabelen). In ieder van deze studies bleek echter een andere contingency-variabele van invloed te zijn op de relaties zodat uit het onderzoek niet blijkt in welke omstandigheden inspraak bij het vaststellen van budgetten een positieve invloed heeft op de prestaties en in welke omstandigheden een negatieve invloed.

Resumerend kunnen we stellen dat het onderzoek naar de gevolgen van budgetparticipatie beperkte resultaten heeft opgeleverd. Weliswaar weten we dat budgetparticipatie een positieve

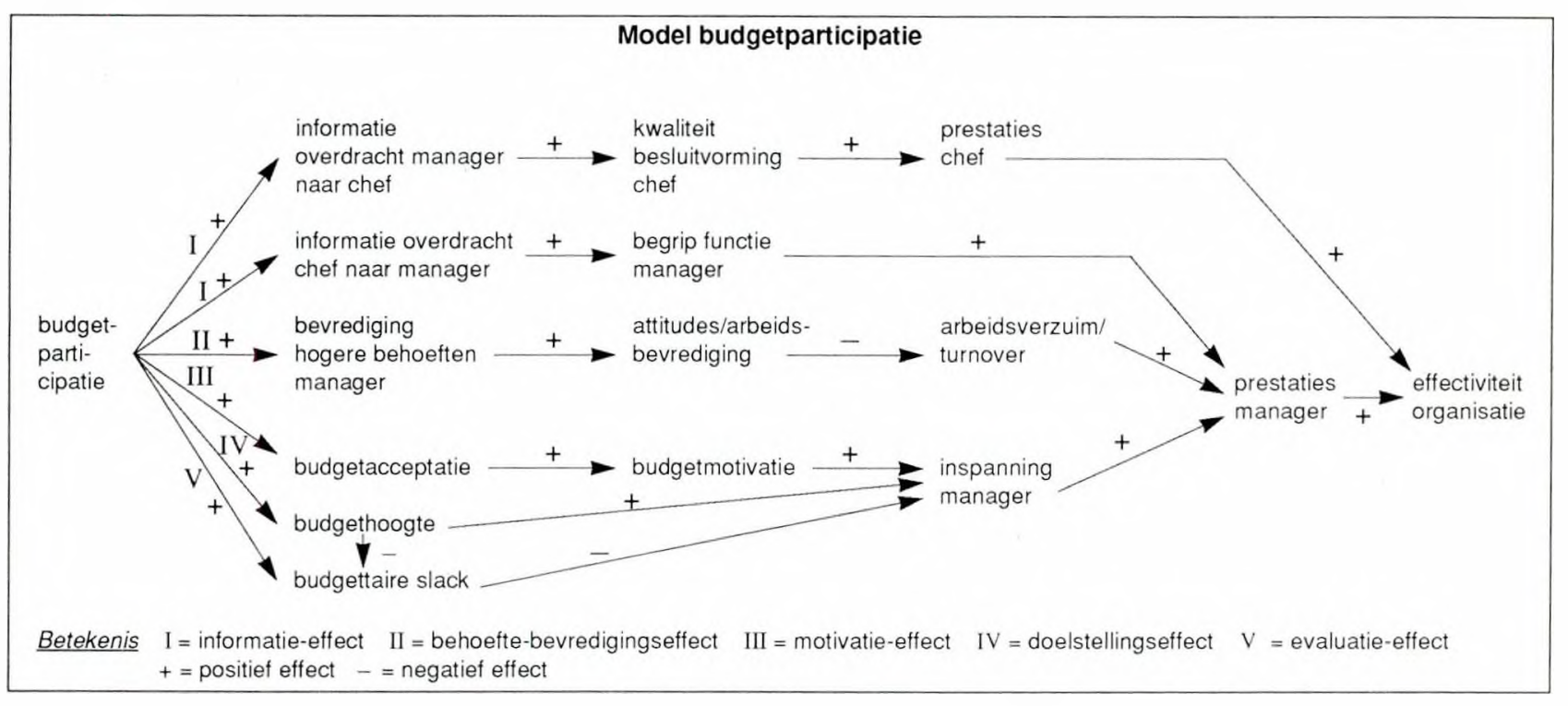




\section{MAB}

invloed heeft op de psychische gesteldheid van managers (attitudes, arbeidsbevrediging en motivatie) maar de uiteindelijke gevolgen voor het gedrag van deze managers (arbeidsprestaties en vorming slack) zijn na 20 jaar onderzoek nog zeer onduidelijk.

Een belangrijke reden hiervan is dat in het onderzoek te weinig rekening is gehouden met de verschillende, elkaar soms tegenwerkende, effecten van budgetparticipatie. Hierop zal in de volgende paragraaf worden ingegaan.

\section{De diverse effecten van budgetparticipatie}

Om een goed inzicht te krijgen in de gevolgen van budgetparticipatie is het van belang om onderscheid te maken tussen de verschillende effecten van budgetparticipatie en de wijze waarop deze invloed uitoefenen op de motivatie, arbeidsprestaties enzovoort van managers. ${ }^{2}$

We kunnen de volgende effecten van budgetparticipatie onderscheiden (zie figuur 1, p. 109):

1 Behoeftebevredigingseffect.

Budgetparticipatie heeft tot gevolg dat de betrokken manager invloed krijgt op de beslissingen van de organisatieleiding waardoor behoeften als zelfrespect, ontplooiing, autonomie enzovoort worden bevredigd (Miller en Monge, 1986).

Dit zal leiden tot een verbetering van de attitudes van de manager ten opzichte van zijn functie en de organisatie en tot een grotere arbeidsbevrediging. Dit zal weer leiden tot een geringer arbeidsverzuim van de manager en tot een geringe behoefte om een andere functie te zoeken (geringere 'turnover') hetgeen zal leiden tot een grotere ervaring in de functie en daardoor tot betere arbeidsprestaties.

Uit onderzoek blijkt dat een verbetering van attitudes en arbeidsbevrediging veelal geen directe invloed heeft op het prestatieniveau van de manager; omgekeerd zal een hoog prestatieniveau wel leiden tot verbetering van attitudes en arbeidsbevrediging (Locke en Latham, 1990).

2 Informatie-effect.

Als gevolg van budgetparticipatie vindt infor- matie-overdracht plaats tussen de manager en zijn chef.

De manager beschikt vaak over meer gedetailleerde informatie op het terrein van zijn functie. Indien deze informatie wordt overgedragen aan zijn chef zal deze chef betere beslissingen kunnen nemen waardoor zijn prestaties zullen verbeteren.

Omgekeerd beschikt de chef van de manager vaak over achtergrondinformatie over beleid en doelstellingen van de organisatie enzovoort. Indien deze informatie wordt overgedragen aan de manager, zal bij de manager een beter begrip ontstaan inzake de door hem uit te voeren werkzaamheden waardoor ook zijn prestaties zullen verbeteren.

3 Motivatie-effect.

Een voorwaarde voor aanwezigheid van motivatie om doelstellingen te realiseren, is dat deze doelstellingen door de betrokkene worden geaccepteerd.

Budgetparticipatie heeft tot gevolg dat de manager invloed krijgt op de vaststelling van de budgetten, hetgeen zal leiden tot een betere acceptatie van de (gebudgetteerde) doelstellingen. Dit zal leiden tot een hogere motivatie om de budgetten realiseren (Erez et al, 1985).

4 Doelstellingseffect.

Uit onderzoek blijkt dat participatie leidt tot een grotere bereidheid van de manager om zich tegenover zijn chef positief op te stellen hetgeen leidt tot een verhoging van de doelstellingen (Latham et al, 1978).

Hogere (gebudgetteerde) doelstellingen leiden tot een afname van de budgettaire slack en tot een grotere inspanning van de manager om de budgetten te realiseren en daardoor tot betere prestaties (Bryan en Locke, 1967).

5 Evaluatie-effect.

Managers worden (mede) beoordeeld naar de mate waarin zij erin zijn geslaagd de voor hen geldende budgetten te behalen zodat hiervan ook (direct of indirect) hun beloning afhangt.

Dit heeft tot gevolg dat managers voordeel hebben bij enige 'ruimte' in de hen toegewezen budgetten (budgettaire slack) en deze ruimte via budgetparticipatie zullen proberen te realiseren (Young, 1985). Budgettaire slack zal lei- 


\section{MAB}

den tot een geringere inspanning van de manager en daardoor tot geringere prestaties (Bryan en Locke, 1967).

Uit het voorgaande kunnen de volgende conclusies worden getrokken (zie figuur 1, p. 109):

1 Budgetparticipatie zal (via het behoeftebevredigingseffect) een positieve invloed hebben op de attitudes en arbeidsbevrediging van managers en (via het motivatie-effect) de motivatie positief beinvloeden.

Dit is in overeenstemming met de in empirisch onderzoek gevonden positieve relatie tussen de mate van budgetparticipatie en de attitudes, arbeidsbevrediging en motivatie van managers.

2 De invloed van budgetparticipatie op budgettaire slack en de prestaties van managers kan niet a priori worden aangeven.

Via diverse effecten leidt budgetinspraak immers tot een afname van budgettaire slack en tot betere prestaties; via het evaluatie-effect zal budgetparticipatie echter juist leiden tot een toename van budgettaire slack en daardoor tot geringe prestaties.

Dit is in overeenstemming met de strijdige en onduidelijke relaties die in het empirische onderzoek werden gevonden tussen budgetparticipatie en de omvang van budgettaire slack en prestaties.

Gesteld kan dan ook worden dat de beperkte onderzoeksresultaten mede worden veroorzaakt door het feit dat budgetparticipatie via elkaar tegenwerkende effecten inwerkt op budgettaire slack en prestaties. Hiermee is in het onderzoek onvoldoende rekening gehouden.

\section{Overige methodologische beperkingen van het onderzoek}

Naast het feit dat onvoldoende rekening is gehouden met de diverse effecten van budgetparticipatie, heeft een aantal methodologische beperkingen van het verrichte onderzoek (vrijwel uitsluitend survey-onderzoek) tot de beperkte onderzoeksresultaten bijgedragen.

De belangrijkste van deze beperkingen zijn:
1 Onvoldoende sturing van het empirische onderzoek door theorievorming.

De theorievorming over de gevolgen van budgetparticipatie, is zeer beperkt gebleven. Dit heeft tot gevolg gehad dat het empirische onderzoek ook niet gericht kon worden op de empirische toetsing van uit de theorie afgeleide hypothesen.

Doordat het onderzoek onvoldoende door theorievorming is gestuurd heeft het een weinig systematisch karakter gekregen.

Toen bijvoorbeeld duidelijk werd dat budgetparticipatie in sommige onderzoeken een positieve en in andere onderzoeken een negatieve invloed bleek te hebben op de prestaties van managers, is door de diverse onderzoekers op weinig systematische wijze geprobeerd vast te stellen in welke omstandigheden budgetparticipatie een positieve invloed heeft op de prestaties en in welke omstandigheden een negatieve invloed.

Zo onderzochten Cherrington en Cherrington (1973) de invloed van het beloningssysteem, Brownell (1983) de invloed van de leiderschapsstijl van de chef van de manager, Bruns en Waterhouse (1975) de invloed van centralisatie van de besluitvorming enzovoort. Gezien deze weinig systematische wijze van onderzoek, is het niet verwonderlijk dat deze pogingen weinig resultaat hebben opgeleverd.

2 Onvoldoende rekening met de organisatiecontext.

In de diverse studies is onvoldoende rekening gehouden met de aard van de afdeling en organisatie waarbinnen de processen zich afspelen. Naar verwachting zal de betekenis van budgetten (en dus ook de effecten van budgetparticipatie) sterk afhankelijk zijn van de aard van de afdeling en organisatie.

Zo zal budgetparticipatie bij bijvoorbeeld een marketingafdeling (met een omzetbudget) naar verwachting andere effecten hebben dan bij een administratieve afdeling (met een kostenbudget). Bij de marketingafdeling kan de gerealiseerde omzet, ook door omstandigheden die de marketingmanager moeilijk kan beïnvloeden, sterk afwijken van de gebudgetteerde omzet terwijl de marketingmanager vaak wel 


\section{MAB}

wordt beoordeeld (en beloond) op grond van opgetreden verschillen tussen omzet en budget.

Het kostenbudget van de afdeling administratie heeft een geheel andere betekenis. De kosten hebben in sterke mate een constant karakter waardoor het taakstellende element veel geringer zal zijn dan in het geval van een omzetbudget. Verwacht mag dan ook worden dat de effecten van budgetparticipatie in beide gevallen sterk zullen verschillen.

In slechts één studie (Brownell, 1985) werd de invloed van de soort afdeling onderzocht. In deze studie bleek budgetparticipatie in research-en developmentafdelingen een positieve invloed te hebben op de prestaties en in marketingafdelingen juist een negatieve invloed. Meer onderzoek op dit gebied is zeer gewenst.

3 Problemen bij definiëring van variabelen.

De vergelijkbaarheid van de diverse onderzoeksresultaten wordt beperkt doordat de diverse studies niet altijd dezelfde definities hanteerden.

Bij het onderzoek naar de invloed van participatie op attitudes van managers, onderzocht bijvoorbeeld Milani (1975) de invloed op attitudes ten opzichte van job en organisatie en Collins (1978) de attitudes ten opzichte van het budgetsysteem.

Ook bij het onderzoek naar de invloed op de prestaties traden verschillen op. Zo onderzocht bijvoorbeeld Brownell (1982a) de invloed van participatie op de prestaties van de manager en Merchant (1981) de invloed op de prestaties van de afdeling van de betreffende manager.

De wijze waarop variabelen werden gedefinieerd is verder naar verwachting van invloed geweest op de gevonden relaties. De prestaties werden vaak gedefinieerd als 'de mate waarin de budgetten zijn gerealiseerd' (budgetperformance). Stel echter dat managers budgetparticipatie hebben gebruikt om budgettaire slack te creëren. In dit geval zal een (fictieve) positieve relatie worden gevonden tussen participatie en prestaties (participatie leidt immers tot gemakkelijker haalbare bud- getten en daardoor tot een hogere 'budgetperformance').

4 Problemen bij meten van variabelen.

Ook als de variabelen op dezelfde wijze werden gedefinieerd werd de vergelijkbaarheid soms beperkt doordat de variabelen op een verschillende wijze werden gemeten.

In het onderzoek van Merchant (1981) werden de afdelingsprestaties bijvoorbeeld gemeten door de manager van de betreffende afdeling te vragen de prestaties van zijn afdeling aan te geven op een 5-puntsschaal (variërend van 'sterk beneden gemiddelde' tot 'sterk boven gemiddelde'), terwijl Govindarajan (1986) de afdelingsprestaties vaststelde door aan de managers vragen te stellen over de mate waarin de afdelingsbudgetten waren gehaald. In vrijwel alle studies werden de variabelen verder gemeten aan de hand van door de managers ingevulde vragenlijsten. In feite werden op die manier niet de variabelen zelf gemeten, maar de perceptie van de manager inzake de variabelen vastgesteld.

Ook dit heeft de onderzoeksresultaten waarschijnlijk beïnvloed.

Zo is het bijvoorbeeld niet ondenkbaar dat een zeer zelfbewuste manager als gevolg van zijn zelfbewustheid de indruk heeft veel invloed te hebben op de budgetvaststelling en tevens de indruk heeft uitstekende prestaties te leveren, waardoor een positieve relatie wordt gevonden tussen participatie en prestaties (in feite bestaat alleen een relatie tussen de perceptie van participatie en de perceptie van de prestaties).

5 Beperkte onderzoekmodellen.

Zoals uit paragraaf 3 is gebleken, is budgetparticipatie een complex verschijnsel dat via diverse effecten inwerkt op budgettaire slack en prestaties van managers. Survey-onderzoek is voor zulke complexe verschijnselen minder geschikt, omdat het opnemen van een groot aantal variabelen en relaties in het onderzoekmodel problemen oplevert. De meeste survey-studies maakten dan ook gebruik van relatief eenvoudige onderzoekmodellen waarin de relaties tussen slechts een beperkt aantal variabelen werd onderzocht. 


\section{MAB}

\section{Aanbevelingen voor toekomstig onderzoek}

Uit het voorgaande is duidelijk geworden dat we ondanks ruim 20 jaar empirisch onderzoek, nog maar weinig weten over de invloed van budgetparticipatie op budgettaire slack en prestaties. We weten wel dat de invloed van budgetparticipatie soms positief en soms negatief is, maar we zijn in het geheel nog niet in staat om aan te geven wanneer dit het geval is.

Als op dezelfde wijze wordt doorgegaan met het verrichten van (op zichzelf wetenschappelijk verantwoorde) survey-onderzoeken, dan zal dat naar verwachting ook de komende 20 jaar weinig relevante resultaten opleveren.

Naar onze opvatting is het verrichten van nog meer survey-onderzoek pas zinvol als dit onderzoek door adequate theorievorming wordt gestuurd.

Het verdient dan ook aanbeveling om allereerst via kwalitatief veldonderzoek als case-studies een beter inzicht te krijgen in de gevolgen van budgetparticipatie in verschillende organisatorische settings. Aan de hand van deze inzichten kan dan theorievorming plaatsvinden over de diverse effecten van budgetparticipatie ${ }^{3}$ en de factoren die van invloed zijn op de omvang van deze effecten zodat hieromtrent zinvolle hypothesen geformuleerd kunnen worden. Deze hypothesen kunnen tenslotte via nieuwe survey-onderzoeken worden getoetst. Om de vergelijkbaarheid van dit onderzoek te vergroten dienen de gebruikte variabelen zo veel mogelijk op dezelfde wijze gedefinieerd en gemeten te worden.

\section{Literatuur}

Argyris, C., The impact of budgets on people, 1952, Controllership Foundation.

Bass, B.M., and H.J. Leavitt, Some experiments in planning and operating, Management Science, July 1963, pp. 574-585.

Becker, S.W., and D. Green, Budgeting and employee behavior, Journal of Business, October 1962, pp. 392-402

Bouma, J.L., Leerboek der bedrifseconomie (deel 1), Delwel Uitgeverij B.V., 1982.

Brownell, P., Participation in budgeting, locus of control and organizational effectiveness, The Accounting Review, October 1981, pp. 844-860.
Brownell, P., Participation in the budgeting process: when it works and when it doesn't, Journal of Accounting Literature, 1982, pp. 124-153.

Brownell, P., The role of accounting data in performance evaluation, budgetary participation, and organizational effectiveness, Journal of Accounting Research, Spring 1982a, pp. 12-27.

Brownell, P., Leadership style, budgetary participation and managerial behavior, Accounting, Organizatons and Society, 1983, pp. 307-321.

Brownell, P., The motivational impact of management-byexception in a budgetary context, Journal of Accounting Research, 1983(a), pp. 456-472.

Brownell, P., Budgetary systems and the control of functionally differentiated organizational activities, Journal of Accounting Research, Autumn 1985, pp. 502-512.

Brownell, P., and M. Hirst, Reliance on accounting information, budgetary participation, and task uncertainly: test of threeway interaction, Journal of Accounting Research, Autumn 1986, pp. 241-249.

Brownell, P., and M. Mclnnes, Budgetary participation, motivation, and managerial performance, The Accounting Review, October 1986, pp. 587-600.

Bruns, W.J., and J.H. Waterhouse, Budgetary control and organization structure, Journal of Accounting Research, Autumn 1975, pp. 177-203.

Bryan, J.F. and E.A. Locke, Goal setting as a means of increasing motivation, Journal of Applied Psychology, 1967, 52, pp. 274-277.

Cammann, C., Effects of the use of control systems, Accounting, Organizations and Society, 1976, pp. 301-314.

Carroll, S.J., and H.L. Tosi, Goal characteristics and personality factors in a management by objectives program, Administrative Science Quarterly, 1970, 15, pp. 295-305.

Chenhall, R.H., Authoritarianism and participative budgeting: a dyadic analysis, The Accounting Review, 1986, pp. 263-271.

Chenhall, R.H., and P. Brownell, The effect of participative budgeting on jobsatisfaction and performance: role ambiguity as an intervening variable, Accounting, Organizations and Society, 1988, pp. 225-233.

Cherrington, D.J., and J.O. Cherrington, Appropiate reinforcement contingencies in the budgeting process, Emperical Research in Accounting: Selected Studies, Supplement to the Journal of Accounting Research, 1973, pp. 225-253.

Collins, F., The interaction of budget characteristics and personality variables with budgetary response attitudes, The Accounting Review, April 1978, pp. 324-335.

Dunk, A.S., Budget emphasis, budgetary participation and managerial performance: a note, Accounting, Organizations and Society, 1989, pp. 321-324.

Dunk, A.S., Budgetary participation, agreement on evaluation critiria and managerial performance: a research note, Accounting, Organizations and Society, 1990, pp. 171-178.

Erez, M., P.C. Early and C.L. Hulin, The impact of participation on goal acceptance and performance: a two-step model, Academy of Management Journal, 1985, pp. 50-66. 
Foran, M., and D.T. DeCoster, An experimental study of the effects of participation, authoritarianism and feedback on cognitive dissonance in a standard setting situation, The Accounting Review, 1974, 49, pp. 751-763.

French, J.R.P., E. Kay, and H. Meyer, Participation and the appraisal system, Human Relations, February 1966, pp. 3-20.

Govindarajan, V., Impact of participation in the budgetary process on managerial attitudes and performance: universalistic and contingency perspectives, Decision Science, 17, 1986, pp. 496-516.

Hofstede, G.H., The game of budget control, Van Gorcum, 1967.

Hopwood, A.G., An accounting system and managerial behaviour, 1973, Saxon House.

Kennis, I., Effects of budgetary goal characteristics on managerial attitudes and performance, The Accounting Review, October 1979, pp. 707-721.

Latham, G.P., T.R. Mitchell, and D.L. Dosset, Importance of participative goal setting and anticipated rewards on goal difficulty and job performance, Journal of Applied Psychology, 63 (1978), pp. 163-171.

Locke, E.A., and G.P. Latham, $A$ theory of goal setting and task performance, 1990, Prentice Hall, Englewood Cliffs.

Likert, R., The human organization, Mc graw-Hill, 1967.

Locke, E.A., and D.M. Schweiger, Participation in decisionmaking: one more look, in B.M. Staw (ed.), Research in Organizational Behavior, Jai Press, 1979, pp. 265-339.

Merchant, K.A., The design of the corporate budgeting system: influences on managerial behavior and performance, The Accounting Review, October 1981, pp. 813-829.

Merchant, K.A., Budgeting and the propensity to create budgetary slack, Accounting, Organizations and Society, 1985, pp. 201-210.

Mia, L., Managerial attitude, motivation and the effectiveness of budget participation, Accounting, Organizations and Society, 1988, pp. 465-475.

Milani, K., The relationship of participation in budget-setting to industrial supervisor performance and attitudes: a field study, The Accounting Review, April 1975, pp. 274-284.

Miller, K.I., and P.R. Monge, Participation, satisfaction and productivity: a meta-analytic review, Academy of Management Journal, 29 (1986), pp. 727-753.

Onsi, M., Factor analysis of behavioral variables effecting budgetary slack, The Accounting Review, July 1973, pp. 535548.

Otley, D., Accounting control and organizational behaviour, Heinemann, 1987.
Searfoss, D., and R. Monczka, Perceived participation in the budget process and motivation to achieve the budget, Academy of Management Journal, 16, 1973, pp. 541-554.

Stedry, A.C., Budget control and cost behavior, Prentice-Hall, 1960.

Steers, R.M., Factors affecting job attitudes in a goal-setting environment, Academy of Management Journal, 19, 1976, pp. 6-16.

Tiller, M.G., The dissonance model of participative budgeting: an emperical exploration, Journal of Accounting Research, 1983, pp. 581-595.

Vroom, V., Some personality determinants of the effects of participation, 1960, Prentice Hall, Englewood Cliffs.

Umapathy, S., Current budgetting practices in US industry, Quorum Books, New York, 1987.

Wood, R.E., and E.A. Locke, Goal setting and strategy effects on complex tasks, in B.M. Staw and L.L. Cummings (eds.), Research in Organizational Behavior, Jai Press, 1990, pp. 73109.

Young, S.M., Participative budgeting: the effects of risk aversion and asymetric information on budgetary slack, Journal of Accounting Research, Autumn 1985, pp. 829-842.

\section{Noten}

1 Bij survey-onderzoek wordt via een steekproef een groot aantal objecten (organisaties, personen enzovoort) geselecteerd waarvan vervolgens een aantal kenmerken wordt gemeten (vaak via vragenlijsten). De verzamelde gegevens worden vervolgens statistisch geanalyseerd. Survey-onderzoeken hebben een grote mate van validiteit en leveren veelal generaliseerbare uitkomsten op.

2 We hebben hierbij gebruik gemaakt van de analyse van Locke en Schweiger (1979) die aandacht hebben geschonken aan de gevolgen van participatie in beslissingsprocessen.

Budgetparticipatie heeft echter een aantal bijzondere aspecten omdat de participatie betrekking heeft op het vaststellen van doelstellingen op grond waarvan de participerende manager later wordt beoordeeld.

3 Om de diverse effecten te kunnen onderscheiden dient vastgesteld te worden via welke 'intervening variables' budgetparticipatie de prestaties beïnvloedt. De 'intervening variables' van de diverse effecten zijn vermeld in figuur 1 . 


\section{MAB}

\section{Bijlage 1: Overzicht empirisch onderzoek budgetparticipatie}

Gevonden relaties met budgetparticipatie

\begin{tabular}{|c|c|c|c|c|}
\hline Studie & $\begin{array}{r}\text { attitudes/arbeids- } \\
\text { bevrediging }\end{array}$ & motivatie & $\begin{array}{r}\text { budgettaire } \\
\text { slack }\end{array}$ & $\begin{array}{r}\text { prestatieniveau } \\
\text { manager }\end{array}$ \\
\hline $\begin{array}{l}\text { Argyris (1952) } \\
\text { Stedry (1960) }\end{array}$ & & + & & + \\
\hline Becker/Green (1962) & & + & & + \\
\hline $\begin{array}{l}\text { Bass/Leavit (1963) } \\
\text { French et al (1966) } \\
\text { Bryan/Locke (1967) }\end{array}$ & + & & & $\begin{array}{l}+ \\
0 \\
-\end{array}$ \\
\hline Hofstede (1967) & + & + & & \\
\hline Caroll/Tosi (1970) & 0 & & & 0 \\
\hline Hopwood (1973) & + & & + & \\
\hline Searfoss/Monczka (1973) & & + & & \\
\hline Cherrington/Cherrington (1973) & + & & & $\mathrm{C}$ \\
\hline Onsi (1973) & + & & - & \\
\hline Foran/DeCoster (1974) & & 0 & & \\
\hline Bruns/Waterhouse (1975) & C & & & C \\
\hline Milani (1975) & + & & & 0 \\
\hline Steers (1976) & + & & & \\
\hline Cammann (1976) & + & & 0 & \\
\hline Collins (1978) & + & & 0 & \\
\hline Kennis (1979) & + & + & & 0 \\
\hline Merchant (1981) & + & + & & \\
\hline Brownell (1981) & & & & C \\
\hline Brownell (1982a) & 0 & & & + \\
\hline Brownell (1983) & $\mathrm{C}$ & & & C \\
\hline Brownell (1983a) & & + & & \\
\hline Tiller (1983) & + & & & + \\
\hline Brownell (1985) & & & & c \\
\hline Merchant (1985) & & & - & \\
\hline Young (1985) & & & + & \\
\hline Brownell/Hirst (1986) & + & & & 0 \\
\hline Brownell/mclnnes (1986) & & 0 & & + \\
\hline Chenhall (1986) & + & & & \\
\hline Govindarajan (1986) & + & + & - & \\
\hline Chenhall/Brownell (1988) & + & & & 0 \\
\hline Mia (1988) & + & 0 & & C \\
\hline Dunk (1989) & & & & C \\
\hline Dunk (1990) & & & & $\mathrm{C}$ \\
\hline Totaal & $+(17)$ & $+(8)$ & $+(2)$ & $+(6)$ \\
\hline & $-(0)$ & $-(0)$ & $-(3)$ & $-(2)$ \\
\hline & $0(2)$ & $0(3)$ & $0(2)$ & $0(6)$ \\
\hline & $\mathrm{C}(2)$ & $C(0)$ & $C(0)$ & $C(8)$ \\
\hline
\end{tabular}

\section{Betekenis symbolen}

$+=$ positieve relatie met budgetparticipatie

- = negatieve relatie met budgetparticipatie

$0=$ geen significante relatie met budgetparticipatie

$\mathrm{C}=$ aard relatie (positief of negatief) afhankelijk van contingency-factoren

De volgende factoren bleken relevant:

- evaluatie/beloningssysteem (Cherrington/ Cherrington, 1973)
- mate centralisatie onderneming (Bruns/ Waterhouse, 1975)

- 'locus of control' manager (Brownell, 1981)

- leiderschapsstijl chef manager (Brownell, 1983)

- aard afdeling (Brownell, 1985)

- attitudes en motivatie manager (Mia, 1988)

- evaluatiestijl chef manager (Dunk, 1989)

- mate overeenstemming over evaluatiecriteria tussen chef en manager (Dunk, 1990) 